\title{
Dimensioning windows for railway infrastructure maintenance: Cost efficiency versus traffic impact
}

Tomas Lidén and Martin Joborn

\section{Linköping University Post Print}

\section{Tweet}

N.B.: When citing this work, cite the original article.

Original Publication:

Tomas Lidén and Martin Joborn, Dimensioning windows for railway infrastructure maintenance: Cost efficiency versus traffic impact, Journal of Rail Transport Planning \& Management, 2016 6(1), pp. 32-47.

http://dx.doi.org/10.1016/j.jrtpm.2016.03.002

Copyright: Elsevier

http://www.elsevier.com/

Postprint available at: Linköping University Electronic Press

http://urn.kb.se/resolve?urn=urn:nbn:se:liu:diva-126777

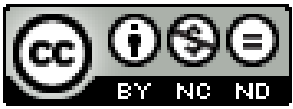




\title{
Dimensioning windows for railway infrastructure maintenance: cost efficiency versus traffic impact
}

\author{
Tomas Lidén*, Martin Joborn
}

Linköping University, Department of Science and Technology, Norrköping SE-601 74, Sweden

\begin{abstract}
The Swedish Transport Administration is introducing a new regime, called maintenance windows, for allocating train free slots reserved for maintenance tasks on the railway infrastructure. In this paper, a model for the assessment and the dimensioning of such maintenance windows is presented, which considers marginal effects on both the maintenance cost and the expected train traffic demand. The aim is to establish quantitative measures that can be used for comparing conflicting capacity requests from infrastructure maintenance and traffic operations on railway networks. The model is demonstrated in a cost benefit analysis for a real life case study on the Swedish Northern Main Line.
\end{abstract}

Keywords: Maintenance planning; Cost benefit analysis; Railway infrastructure

\section{Introduction}

Railway infrastructure maintenance is of crucial importance in order to obtain a well functioning transportation system. The actual maintenance work consists of a large amount of different activities, requiring considerable resources and large budgets. The European countries are reported to allocate $15-25$ billion $€$ annually on maintenance and renewals for a railway system consisting of about $300000 \mathrm{~km}$ of track, giving an average of 70,000€ per km track and year (see EIM-EFRTC-CER Working Group (2012)).

There is however an inherent conflict in deciding how to assign maintenance work slots and train operation paths since these activities are mutually exclusive. This planning conflict becomes crucial on lines with high traffic density and/or around the clock operation - especially when traffic demand and maintenance needs are increasing. This is the case in Sweden, where passenger and freight trains are mixed on the same infrastructure and a large increase in passenger traffic, both regional and inter-regional, have forced many freight trains to be run during night time, leaving very few opportunities for maintenance.

In addition, a far reaching deregulation has been going on since the 1980s in Europe, with the overall purpose of opening up for commercial competition in the railway area. For infrastructure maintenance, this trend has extended the use of maintenance contractors, which raises more concerns regarding contractual forms, public procurement as well as planning.

All these factors - the large volumes, the interrelation between maintenance and traffic, the organizational aspects - motivate efficient and coordinated planning as well as more research. This is further accentuated by increasing needs for transportation regarding volumes, weights, speeds, safety and comfort, which, together with an ageing infrastructure, will increase the demands for maintenance and renewals. Historically, research about scheduling and planning has however focused more on train operation problems than on infrastructure maintenance. Specifically, the coordinated planning of infrastructure maintenance and train operations has received little attention. In such planning, with conflicting capacity requests that should be balanced, we need quantitative measures that can be used as evaluation criteria - which is the issue to be addressed here.

\footnotetext{
*Corresponding author. Tel.: +46-70-755 0020

Email address: tomas.liden@liu.se (Tomas Lidén)
} 
In this paper we present a model for evaluating the impact of different maintenance window designs on both train traffic and maintenance cost and apply it on railway lines with a homogeneous train traffic. The major contributions of this work are (a) an analytical model for calculating the maintenance cost depending on the available train free time, (b) a framework for quantifying and comparing conflicting capacity requests from maintenance and traffic on railway networks, and (c) demonstration of the approach on a real life case study. For the train operations we apply standard transport economy models on the detailed level of individual travel choices and transport service changes. Although we mainly will discuss single track situations, the models are applicable to any type of rail line.

The paper is organized as follows: In the next section we describe the background and motivation for the studied problem followed by a literature review in Section 3. The modelling approach is outlined in Section 4, followed by the mathematical formulations for assessing the effects on maintenance cost (Section 5 ) and traffic and transportation (Section 6). In Section 7 the use of these models on a real life case study is reported. Finally, we conclude with summary and discussion in Section 8 . For better readability we consider a somewhat simplified case in Section 5 while the complete and detailed maintenance cost model is presented in AppendixA.

\section{Problem description and assumptions}

All non-train activities that require secure access to the railway infrastructure must obtain a (work) possession (RailNetEurope (2013)). Up to now, the planning regime adopted in Sweden has been to let the maintenance contractors apply for these work slots, which usually is done as late as possible. If no room is reserved for maintenance in the timetable it can be difficult to find suitable possessions, which forces the contractors to perform their work on odd times and/or divide the tasks into small chunks which leads to inefficiency and cost increases. If the work cannot be split into smaller tasks, then the timetable must be altered and train operations rescheduled. Statistics from 2012, regarding the Swedish main line network which is $14,700 \mathrm{~km}$ long, show that there were about 16,000 work possessions applied for during the timetable period. Several of these triggered train path and timetable changes, but the exact figures are not known. As an indication, the total amount of timetable changes in the same period were in the order of $20-30,000$

To increase the possibility for suitable work possessions, a new planning regime is now being introduced in Sweden, called maintenance windows, where the infrastructure manager will propose regular, 2-6 $\mathrm{h}$ train free slots before the timetable is constructed. Thus, the maintenance windows are given as a input to the yearly timetable process. In addition, the maintenance windows will be dimensioned and constructed before the procurement of maintenance contracts and will remain more or less unchanged during the contract period, giving stable planning and quotation conditions for the contractors. The goal is to perform almost all planned maintenance on work possessions within the stipulated maintenance windows. Note that maintenance windows are predetermined train free slots in the timetable, while possessions are the actual reservations for specific work tasks.

Hence, the basic idea is to go from a situation with many, small and fragmented work possessions squeezed into an already published timetable (which causes changes and disturbances for the train operations), to a situation with few, large and regular maintenance windows preplanned before the timetable is constructed and the maintenance contracts procured. The overall aim is to increase efficiency, reduce cost as well as planning burden and also to improve robustness and punctuality. We will not analyse all these aspects but will focus on the consequences for maintenance, train traffic and transportation demand. A more complete study of the pro's and con's when introducing maintenance windows must consider several other factors, like the long term unavailability of train capacity, network wide effects, planning efficiency etc.

The dimensioning and construction of maintenance window patterns is a long term planning problem of crucial importance, since it lays the foundation for both the maintenance work and the traffic operation. It must be based on reasonable predictions about the maintenance work volumes as well as the traffic demand for period lengths of 5-10 years (corresponding to the maintenance contract length - which is $5+2$ years in Sweden). 


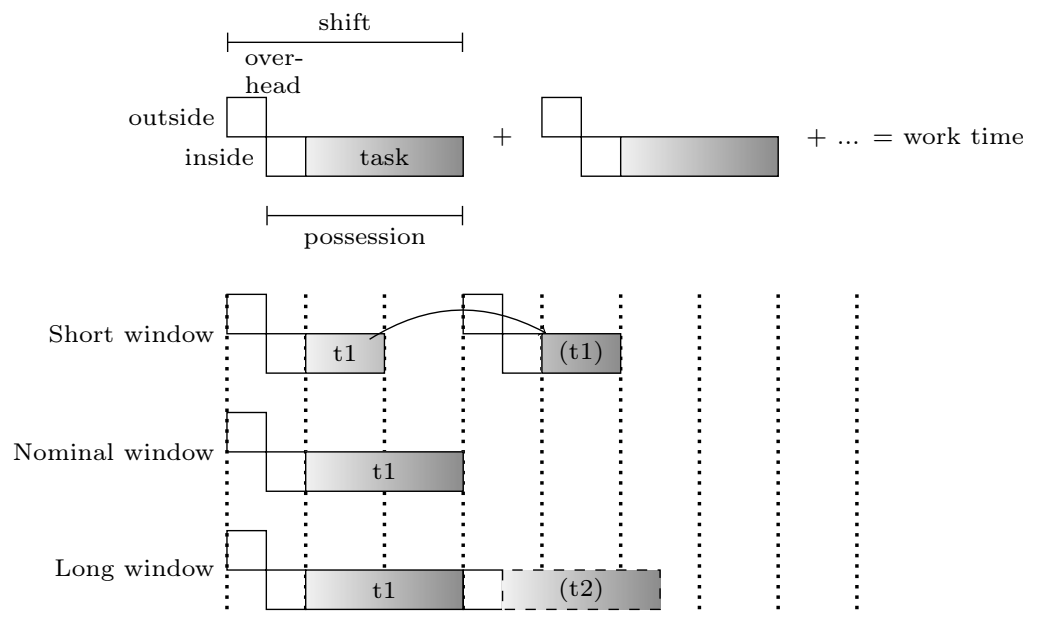

Figure 1: Division of work time and the three window size cases.

Now we turn to the content and organization of the actual maintenance jobs. A maintenance work shift typically consists of three parts:

Preparation: Crew and equipment must be transported to the working site, where the resources will be organized, prepared and set up. The working area must be secured, by proper signalling and electrification measures which includes registration and acknowledgement from the traffic control centre(s).

Maintenance: The actual work task(s) can be of varying type, where some tasks (e.g. inspection and vegetation clearance) require short times, say $1 / 2-1$ hour, while others (e.g. welding, switch machine work) take longer to finish, say 2 - 6 hours.

Termination: When the maintenance task has been finished, the site must be cleared, resources and safety measures removed and finally the responsibility handed back to the traffic control centre(s).

We will label preparation and termination as overhead time, while the actual maintenance job is called task time. Together they form the shift time and the sum of all shifts is called work time. Our basic assumption is that the tasks are divisible such that, e.g. a $2 \mathrm{~h}$ task can be performed on two possessions. The overhead time, on the other hand, is directly proportional to the number of possessions. Further we will consider that some part of the overhead time can be performed outside the track possessions, while the rest must be done inside it. This terminology is illustrated in Figure 1, which also shows the three different window size cases discussed below and exemplified in Table 1.

We distinguish between the following cases regarding window size:

- Short - when the task must be divided into two or more possessions,

- Nominal - when precisely one task can be performed per possession, and

- Long - when more than one task can be performed within the same possession.

The example in Figure 1 and Table 1 considers a $2 \mathrm{~h}$ task, which require $1 \mathrm{~h}$ of overhead time - half of which must be done inside the possession. The nominal window is then $2.5 \mathrm{~h}$, which gives a shift time of 1 $+2=3 \mathrm{~h}$. If only $1.5 \mathrm{~h}$ windows are given the work must be split into two $2 \mathrm{~h}$ shifts, giving a work time of $4 \mathrm{~h}$ per task. The task time $(2 \mathrm{~h})$ is the same in both cases while the sum of possession times has increased from 2.5 to $3 \mathrm{~h}$ and the overhead goes from 1 to $2 \mathrm{~h}$. If a $5 \mathrm{~h}$ window is used, it will allow for performing two such tasks within the same possession - possibly with an extra overhead for moving the crew and equipment (say $0.5 \mathrm{~h}$ ). In this case two tasks can share the same overhead and we get a shift time of $1.5 \mathrm{~h}$ (overhead) + $4 \mathrm{~h}($ task $)=5.5 \mathrm{~h}$, which reduces the work time per task to $2.75 \mathrm{~h}$ (as compared to 3 and $4 \mathrm{~h}$ for the 2.5 and 


\begin{tabular}{lrrrrrr}
\hline \multicolumn{2}{c}{ Window size } & \multicolumn{5}{c}{ Time allocation [h] per task } \\
& & Task & Possession & Overhead & Shift & Work \\
\hline Short & 1.5 & 2.0 & $2 \times 1.5$ & $2 \times 1.0$ & $2 \times 2.0$ & 4.0 \\
Nominal & 2.5 & 2.0 & 2.5 & 1.0 & 3.0 & 3.0 \\
Long & 5.0 & 2.0 & $5.0 / 2$ & $1.5 / 2$ & $5.5 / 2$ & $5.5 / 2$ \\
\hline
\end{tabular}

Table 1: The effect of varying window size for a $2 \mathrm{~h}$ task with $0.5+0.5 \mathrm{~h}$ overhead time

$1.5 \mathrm{~h}$ windows). We can also note (see Table 1 that the share of overhead time per shift is $50 \%, 33 \%$ and $27 \%$ for the small, nominal and large window case. As shown by this simple example the choice of window size will determine the total maintenance cost.

\section{Literature review}

In this section we review research publications that deal with similar issues and compare them to the approach we are interested in. Although lots of research has been done regarding maintenance techniques, engineering, reliability, asset and maintenance management (see e.g. Ben-Daya et al. (2016)), very little have been published regarding planning and scheduling of infrastructure maintenance together with railway traffic. In Lidén (2015a) only 60 references (less than 10 published before 2005) have been found that use mathematical methods and optimization for solving infrastructure maintenance planning problems and several important problems are identified that have not yet been addressed. Considerably more has been done in other application domains, such as electricity and road networks, machine, job shop, aircraft and rolling stock scheduling as shown already in Dekker (1996).

As will be shown below, virtually all previous publications regarding railway infrastructure maintenance focus either on maintenance or traffic while keeping the other more or less fixed, while we want to handle them jointly. Only a few of the references treat both types of activities as variable entities. Further, the objective usually addresses only one of the aspects, while we want to consider and balance the conflicting interests of both maintenance and operations.

A well studied problem is how to plan inspection, preventive maintenance and renewal actions, which will dimension the maintenance volumes, for networks that degrade due to the operational load. See e.g. Durango-Cohen and Madanat (2008) regarding general networks and application to road pavement maintenance. In the railway field, specific subsystem components / maintenance actions have been studied, like ballast / tamping (Zhao et al. (2006); Lyngby et al. (2008)), rail / grinding (Lyngby et al. (2008); Liu et al. (2014); Gustavsson et al. (2014)) and electrical power feeding / replacement (Chen et al. (2013, 2014)). In all these works, policies for inspection, maintenance and renewals are developed with no concern about how the detailed scheduling and interaction with operations should be resolved. The objective is usually to reduce the life cycle cost and/or increase safety and reliability.

For the maintenance window planning considered in this paper, we need to study the planning of work possessions and how they impact the train traffic. The classic paper Higgins (1998) presents the problem of scheduling maintenance jobs and assigning them to work crews on a single track line with a given train traffic timetable. The objective is a weighted sum of expected interference delay (train delays due to late ending job as well as job delays due to late trains) and prioritized finished times (as many trains as possible should run on better track). This is a rare example of using a measure that capture both maintenance and train activities. The resulting non-linear model is solved heuristically with a greedy construction phase followed by tabu search. Another approach is taken in Budai et al. (2006) where they study the problem of clustering preventive maintenance possession for small routine tasks and larger projects together in order to minimize possession and maintenance cost, without any other consideration to the train traffic. A third example is the model for assigning regular work possession patterns (or so called single-track grids) described by van Zante-de Fokkert et al. (2007), where every part of the infrastructure is made available for maintenance at least once every 4 weeks. The primary objective is to minimize the maintenance cost. Consideration to the 
traffic is handled manually when constructing the single-track grids but no method for dimensioning these patterns is given.

Some authors have studied the problem of how to introduce a limited number of maintenance possessions into an existing operative traffic plan by making small adjustments to the trains, e.g. Albrecht et al. (2013) who aim at decision support models for real-time operational control centers on single-track lines. The objective is to reduce delays for both trains and maintenance work and the optimization problem is solved with heuristic methods. A similar problem is studied by Forsgren et al. (2013), who address the timetable revision planning case, handle a network with both single and multi-track lines, allow trains to be rerouted or cancelled and consider different running times depending on train stops. A hierarchical objective function is used for minimizing the number of cancelled trains and the prolongation of running times. The scheduling problem is solved with a clique-based mixed integer-linear model approach. These two papers are the only references found where both maintenance and trains are scheduled.

Several papers (e.g. Peng and Ouyang (2012); Borraz-Sánchez and Klabjan (2012)) have been written about the maintenance team scheduling problem, were a given set of maintenance jobs are to be scheduled on a set of maintenance teams. The objective is to find good routings that minimize the maintenance cost, while traffic considerations are handled by imposing constraints on which jobs that can be performed simultaneously.

In the above references, the purpose is to schedule maintenance so as to minimize cost or timetable changes while treating traffic either as a given timetable (possibly adjustable) or implicitly as scheduling constraints. Boland et al. (2013) on the other hand address the problem of adjusting a given maintenance plan for a complete transportation chain so as to maximize the transportation throughput. Traffic is handled as flows of trains and the maintenance activities will impose reductions on the link capacities in the network. A similar approach is used in Savelsbergh et al. (2014) who use a given maintenance plan and optimize a transportation plan for a coal freight network. From these plans an assessment of the asset reliability, resource requirements and contract compliance can be made, supported by a decision support system where several performance indicators and visualization possibilities are demonstrated.

A paper that discusses the importance of different timetable assumptions used in the appraisal of railway investments is Eliasson and Börjesson (2014). Here a general transport economy modelling framework is used in conjunction with capacity and travel time formulas to show how different timetables will affect cost benefit analysis studies.

In our work, a strategic planning case is studied were we want to dimension (and eventually construct patterns of) maintenance windows, such that both maintenance cost and traffic limitations are minimized. Furthermore, the timetable is unknown (not yet constructed) while the maintenance need is given as predicted work volumes with preferred shift lengths. Thus we have the same type of planning situation as Eliasson and Börjesson (2014) and can use similar models for the traffic. The type of assessment we're interested in, is the same as for Savelsbergh et al. (2014), but instead of using a given maintenance schedule we want to dimension the train free windows. Also, we consider a railway system with mixed traffic and shared capacity allocation handled by an infrastructure owner instead of a dedicated freight transportation network as done in Boland et al. (2013) and Savelsbergh et al. (2014). The results of our work can then be used as input to a scheduling situation similar to the one described by van Zante-de Fokkert et al. (2007) although the Swedish case will use a mixture of and other frequencies of track access.

\section{Model outline}

In this section the modelling approach is outlined, while the mathematical details are given in the forthcoming sections and AppendixA. The purpose of the model is to study the marginal effects on (a) the maintenance cost, and (b) a presumed homogeneous traffic demand, when introducing a maintenance window of varying temporal size. By "marginal" we mean how much the change (in cost etc.) will be as compared to a nominal case. Note that the traffic is not given as a true timetable but as an assumed demand for a certain frequency of trains, which may vary over time.

We consider a line stretch of length $L[\mathrm{~km}]$ and a time horizon of duration $\mathrm{H}[\mathrm{h}]$, where homogeneous train traffic is run in both directions with a wanted time interval of $\Delta[h]$ and a running speed $v[\mathrm{~km} / \mathrm{h}]$. 

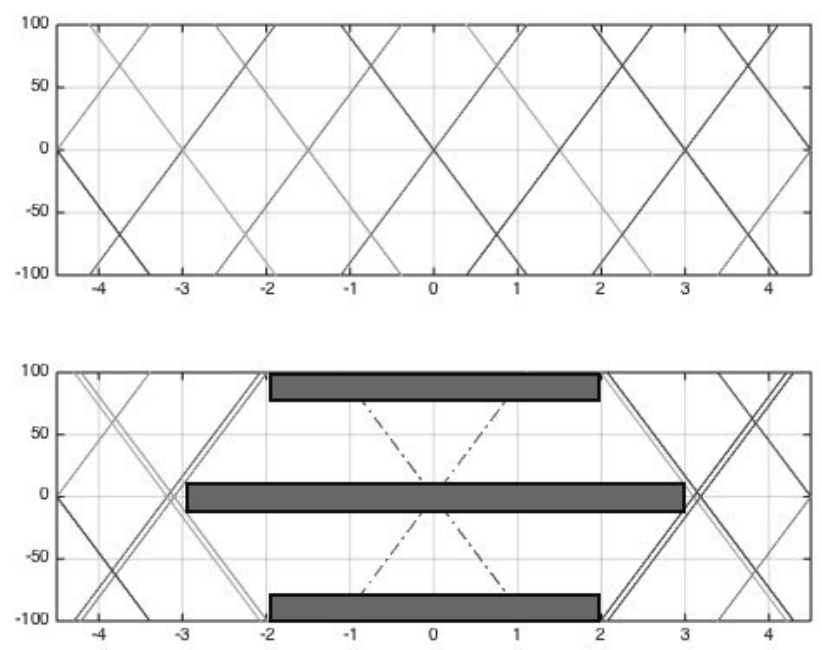

Figure 2: Illustration of train traffic without (above) and with (below) a maintenance window that closes the line. Time on the $\mathrm{x}$ axis and distance on the $\mathrm{y}$ axis. The dashed lines indicate rejected trains. The central and peripheral durations are marked with grey boxes. Detailed stopping and runtime supplements are not shown.

Trains running in the same direction must be separated by at least a headway $\lambda[h]$. On single track lines, opposing trains can only meet at meet/pass loops, spaced with a distance $l[\mathrm{~km}]$, which result in stopping and runtime supplements. The total travel time in the realizable timetable can thus be estimated as a function $r(L / v, l, \Delta)$ of the running speed, the loop distance and the wanted time interval of trains.

When introducing a maintenance window, as illustrated in Figure 2, the central track section will get the longest train free time, which we denote as the central duration, while the outermost sections of the line stretch get the shortest window size - called peripheral duration. The difference in central and peripheral duration is due to the train running times and in order to make room for the maintenance window, the wanted train departures must either be rejected or moved so as to provide a train free slot. The example in the illustration is a single-track case with $L=200, \Delta=1.5, v=90, \lambda=5 / 60$ and a central maintenance window, $t^{w}=6$. The timetable solution in Figure 2 is that one demanded train pair has been rejected (dashed lines) and two departures have been adjusted about $1.6 \mathrm{~h}$, in turn pushing two more train pairs about $0.2 \mathrm{~h}$, giving a total departure adjustment of about $3.6 \mathrm{~h}$ in each direction.

This way of reasoning can also be applied on double-track lines. If the line is completely closed by the maintenance window the outcome is very similar. Alternatively, the maintenance window may be inflicted on only one of the tracks, which gives a possibility to run trains in single-track traffic past the maintenance site (on the non-closed track). Thus, less rejections and departure adjustments are needed, although additional runtime supplements are required to account for the resolution of track conflicts and possible speed reductions past the working site.

To evaluate the system effect of the maintenance window, we need cost functions for the effects on maintenance as well as the train traffic. The maintenance need can be given as yearly volumes, e.g $V_{j k}$ hours of tasks $j$ on track section $k$, with given task length $w_{j}[h]$. For a certain maintenance window duration $t^{w}[h]$, all longer work tasks needs to be split which increases the overhead costs while short ones can be jointly performed during the same possession. Thus the marginal maintenance $\operatorname{cost} C^{m}$, as compared to a nominal window size, can be calculated as a function $C^{m}=\sum_{j k} C_{j k}^{m}\left(V_{j k}, t^{w}\right)$ where $C_{j k}^{m}$ is the change in maintenance cost for task $j$ on track section $k$. We develop the detailed equations for $C^{m}$ in Section 5 and AppendixA.

For the wanted and realizable train traffic, a similar cost change $C^{t}$ due to the maintenance window can be calculated. For freight trains we base it on the number of rejected train demands $\left(y^{r}\right)$, the amount of 
departure adjustment $\left(y^{a}\right)$ and runtime difference $\left(y^{d}\right)$. For passenger traffic we also need to consider the consequential effects on travel behaviour, when traffic supply is changing, which will affect both travellers (consumers), operators (producers) and society. In summary, the marginal traffic cost can be calculated as a function $C^{t}\left(y^{r}, y^{a}, y^{d}\right)$, which is elaborated in Section 6 .

By using the two functions $C^{m}$ and $C^{t}$ we can now calculate the net effect from choosing different maintenance window sizes $t^{w}$. This can be used for assessing and comparing different scenarios or for dimensioning optimal window sizes.

\section{Maintenance cost model}

In this section we present a mathematical model for evaluating the impact of maintenance windows on the maintenance cost, according to the principles given in the problem description (Section 2) and as outlined in the previous section. For the demanded maintenance work we will calculate the needed number of work shifts, which will depend on how the selected window time correspond to the nominal time for each job type - along with overhead settings etc. Thus we can calculate how the maintenance cost changes for different window sizes.

Here we will make three simplifications in order to achieve better overview and readability. First, we will only consider one track section. Secondly, we will assume that all overhead time is done outside of the possession and finally, that the overhead time is independent of the possession time. A complete model without these simplifications is presented in AppendixA

From now on we will use the superscript $n$ for the nominal (standard possession) time and $w$ for the considered window time. With this convention, the notation is as follows:

$J \quad$ Set of maintenance job types $j$

$V_{j} \quad$ Maintenance volume (time) for job type $j$

$w_{j} \quad$ Task time for job $j$

$u_{j} \quad$ Overhead time for job $j$

$t_{j}^{n} \quad$ Nominal possession time (corresponding to the task time) for job $j$

$a_{j}^{n} \quad$ Number of work shifts for job type $j$ with nominal possession time $t_{j}^{n}$

$t_{j}^{w} \quad$ Window time for job type $j$

$a_{j}^{w} \quad$ Number of work shifts for job type $j$ with the considered window time $t_{j}^{w}$

$T_{j}^{n}, T_{j}^{w} \quad$ Total work time with $t_{j}^{n}$ and $t_{j}^{w}$ respectively

$c_{j} \quad$ Hourly cost rate (daytime) for job type $j$

$\rho_{j k}^{w} \quad$ Compensation factor if the window is placed on evening, night or weekend working hours

$C^{m} \quad$ Total cost difference when using the considered window time vs nominal possession time

First we establish the following basic relations, as described below:

$$
\begin{aligned}
V_{j} & =w_{j} a_{j}^{n} \\
T_{j}^{n} & =\left(u_{j}+t_{j}^{n}\right) a_{j}^{n}=\left(u_{j}+w_{j}\right) a_{j}^{n} \\
T_{j}^{w} & =\left(u_{j}+t_{j}^{w}\right) a_{j}^{w}
\end{aligned}
$$

Equation (1) give the maintenance volume for each task type, while (2) and (3) give the total work time for the nominal and the window case respectively.

Since the same maintenance volume must be performed no matter which window time is chosen and since the maintenance tasks are divisible, we can establish how the number of work shifts vary with window size:

$$
\begin{aligned}
V_{j} & =w_{j} a_{j}^{n}=t_{j}^{w} a_{j}^{w} \\
\Rightarrow a_{j}^{w} & =a_{j}^{n} * \frac{w_{j}}{t_{j}^{w}}
\end{aligned}
$$

By subtracting (2) from (3) and using equation (5) we can derive formulas for calculating the difference in total work hours when choosing a certain window time compared to using the nominal possession time: 


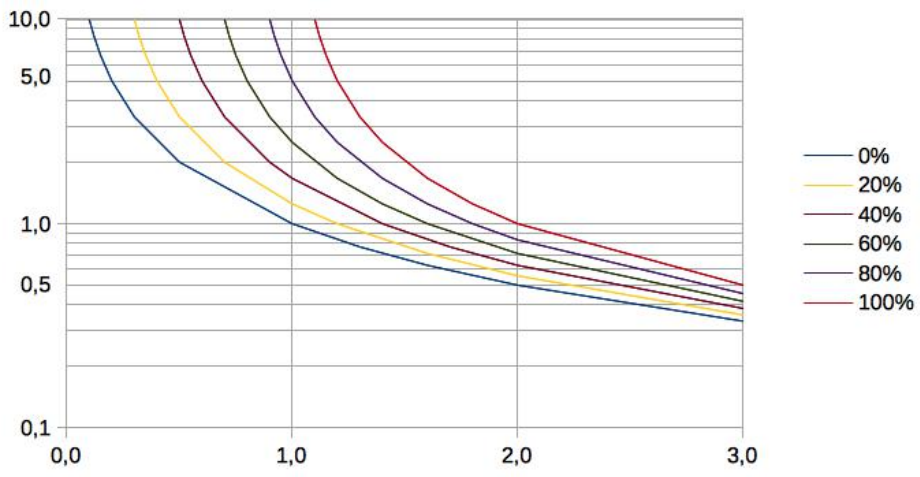

Figure 3: Normalized time difference (y axis) vs normalized window size ( $\mathrm{x}$ axis) for different overhead settings. At $\mathrm{y}$ value 1 there is no cost difference, while above/below that line the cost increases/decreases. At $\mathrm{x}$ value 1 the window size equals the task time, while to the left/right of that line it is shorter/longer. Time difference is normalized by the total nominal overhead, while window size and inside overhead time is normalized by the task time. [y axis $(\operatorname{logarithmic}): 1+\frac{T^{w}-T^{n}}{u a^{n}}, \mathrm{x}$ axis: $t^{w} / w$, curves: $\left.u^{i} / w\right]$

$$
\begin{aligned}
& T_{j}^{w}-T_{j}^{n}=a_{j}^{n}\left[w_{j} * \frac{t_{j}^{w}+u_{j}}{t_{j}^{w}}-\left(t_{j}^{n}+u_{j}\right)\right] \\
& T_{j}^{w}-T_{j}^{n}=a_{j}^{n} * \frac{u_{j}}{t_{j}^{w}}\left[w_{j}-t_{j}^{w}\right]
\end{aligned}
$$

Equations (6) and (7) only differ regarding which parameters that have been eliminated. In (6) we have kept the nominal possession time $t_{j}^{n}$ while in (7) $t_{j}^{n}$ has been eliminated (by using that $t_{j}^{n}=w_{j}$ ).

The equations show that the number of work shifts as well as the total work time difference is inversely proportional to the chosen window time. If we divide the time difference $\left(T^{w}-T^{n}\right)$ with the total nominal overhead time $\left(u a^{n}\right)$ - see (7) and A.7) - we get a normalized time difference, which is illustrated in Figure 3. In this figure we have added the offset value 1 to denote when there is no time difference, also making it possible to use a logarithmic scale. The normalized time difference value is plotted as a function of the normalized window size, expressed as a ratio of the task time $\left(t^{w} / w\right)$. The blue curve follows from (7) and applies when all overhead work is done outside the possession. The diagram also shows curves for increasing amount of overhead work inside the possession (again expressed as a ratio of the task time), which have been generated with the full equations in AppendixA We see that the time difference quickly rises when $t^{w}$ tends to $u^{i}$, which means that most of the possession time will be spent on overhead activities. Apart from showing the cost neutral time window size (y axis value $=1$ ) and how quickly the time difference increases / decreases, the diagram also shows that having all overhead outside of the possession (the blue curve, $\left.u^{i} / w=0 \%\right)$ is most beneficial. This is as expected since the complete possession time can then be used for the actual maintenance tasks.

Finally, we can calculate the marginal cost for selecting a window size $t_{j}^{w}$ other than the nominal possession time $t_{j}^{n}$ as follows:

$$
\begin{aligned}
C^{m} & =\sum_{j} c_{j}\left[\left(1+\rho_{j}^{w}\right) T_{j}^{w}-T_{j}^{n}\right]=\sum_{j} c_{j}\left[T_{j}^{w}-T_{j}^{n}+\rho_{j}^{w} T_{j}^{w}\right] \\
& =\sum_{j} c_{j} a_{j}^{n}\left[w_{j} A-u_{j}+\rho_{j}^{w} w_{j} B\right]=\sum_{j} c_{j} V_{j}\left[A-u_{j} / w_{j}+\rho_{j}^{w} B\right]
\end{aligned}
$$

\footnotetext{
${ }^{1}$ Equation A.7 has been used with the overhead parameters set to $u^{n o}=u^{w o}=u-u^{i} ; u^{n i}=u^{w i}=u^{i}$.
} 
where

$$
A=\frac{u_{j}}{t_{j}^{w}}, \quad B=\frac{t_{j}^{w}+u_{j}}{t_{j}^{w}}
$$

Here equation (8) simply sums up the work time difference (including an overtime compensation factor) multiplied by the hourly cost rate per job type. Then we insert (3) and (7) to get equation (9). In AppendixA we give the corresponding formulas for the general case along with more elaborate variants of the factors $A$ and $B$. As can be seen, we now have established an expression for calculating the change in maintenance cost as a function of the maintenance volumes and the choice of window size (along with overhead and task times). As noted above, the cost is inversely proportional to the window size (see factors $A$ and $B$ ). Again we see that the cost change will quickly rise when $t^{w}$ tends to $u^{i}$, since the denominators of $A$ and $B$ (see A.9p) will then tend to 0.

\section{Effects on traffic and transportation}

In this section we present models for evaluating the effects of maintenance windows on the train traffic and transportation cost. Two cases are considered, namely (a) the impact on long distance freight traffic, due to changes in scheduling and transportation times which will affect the transportation cost, and (b) the impact on passenger travel due to changes in perceived travel cost, which in turn will affect the travel demand. Hence, we will include both the customer and operator view for passenger traffic, while mainly operator costs will be used for the freight traffic. The latter restriction is due to the problem of finding realistic economic evaluation models for the freight customers since the values for transported goods and timely delivery can be unknown, concealed or varying over time. We consider a homogeneous and symmetric traffic case where each train service has an identical one running in the opposite direction.

In the following subsections we describe the calculation models that have been adopted for freight traffic (see 6.1) and passenger traffic (see 6.2). We use the same models as described in Eliasson and Börjesson (2014) and Banverket (2009), with some adjustments for handling more details regarding trains and services. Since this builds on existing knowledge, we keep the text brief and introduce concepts, notation and equations in running text. For the freight traffic we will elaborate on how the cost will change step by step when introducing maintenance windows of increasing size. Some of the notation has been given already in Section 4. but we start by listing some common and important definitions:

$L \quad$ Line stretch length

$l \quad$ Distance between meet/pass loops

$v \quad$ Normal train running speed

$H \quad$ Scheduling horizon

I Set of train services $i$ to consider, running in one direction. Each service has an identical train running in the opposite direction.

$e_{i} \quad$ Departure (event) time for train service $i$ when entering $L$

$r_{i} \quad$ Travel (running) time for train service $i$ along $L$ and within $H$

$m_{i} \quad$ Number of opposing trains for train service $i$ during the scheduling horizon

When needed, we distinguish between train service values for a schedule without $\left(e_{i}^{0}, r_{i}^{0}, m_{i}^{0}\right)$ and with $\left(e_{i}^{w}, r_{i}^{w}, m_{i}^{w}\right)$ the maintenance window.

\subsection{Freight traffic cost model}

Freight traffic normally have less strict requirements on departure and arrival times than passenger traffic. Hence the train slots can be adjusted within certain limits, given by the opening hours of the freight terminals. As long as the freight is delivered within the wanted day there is only a minor customer (or delay) penalty. If the shipment will be delayed until the next day however, there is a large step cost inflicted. Therefore we base the freight traffic cost on: (i) whether a train service $i$ is rejected $\left(y_{i}^{r}=1\right)$ or not $\left(y_{i}^{r}=0\right)$, (ii) the amount of departure adjustment $\left(y_{i}^{a}\right)$, (iii) the runtime difference $\left(y_{i}^{d}\right)$.

Train services will be rejected at a high $\operatorname{cost} c^{r}$ when the necessary departure adjustment exceeds a limit $q^{\max }$ - to be run at some other time. We label the set of all rejected train services $I^{r} \subset I$. 
Departure adjustment, calculated as the difference in departure time $\left(y_{i}^{a}=e_{i}^{w}-e_{i}^{0}\right)$, may be needed to make room for the wanted maintenance window. All adjusted train services belong to the set $I^{a} \subset I$. We will assume that the departure adjustment will make the rolling stock circulations less efficient at a cost $c^{a}$ proportional to the amount of adjustment - dominated by the capital cost for the rolling stock.

Rejections and departure adjustments may give different number of opposing trains and a change in line capacity usage, which in turn may affect the train travel times for all train services $I \backslash I^{r}$ that are operated. The travel time differences $\left(y_{i}^{d}=r_{i}^{w}-r_{i}^{0}\right)$ will affect the time dependent operating cost $c^{d}$ (usually $>c^{a}$ ), which include salaries, fuel, energy etc as well as capital cost.

The marginal freight traffic and transportation cost for introducing the maintenance window can now be calculated as a sum of the costs for rejected services, adjusted departures and travel time differences:

$$
C^{t f}=\sum_{i \in I^{r}} y_{i}^{r} c^{r}+\sum_{i \in I^{a}} y_{i}^{a} c^{a}+\sum_{i \in I \backslash I^{r}} y_{i}^{d} c^{d}
$$

The costs corresponding to rejected and adjusted departures are straight forward to calculate. The travel time difference however depends on two factors: the number of opposing trains $\left(m_{i}\right.$ on single tracks) and the line capacity usage $U$ (a value in the range $[0,1]$ ). We follow the same type of model as used by the Swedish Transport Administration (see Banverket (2009)). Normally, the capacity usage is calculated for each track section $k$ and the highest value is used for the whole line. But since we study a uniform single track line stretch with equal spacing of meet/pass loops and homogeneous traffic, we can simplify the calculation. In the following we will use a coordinate system $([-H / 2, H / 2],[-L / 2, L / 2])$ (see Figure 4a) and since all quadrants are symmetrical we perform the calculation for the positive one $([0, H / 2],[0, L / 2])$. For better readability we set $H^{\prime}=H / 2$ and $L^{\prime}=L / 2$. The line capacity usage can then be calculated as follows (ibid):

$$
\begin{aligned}
U & =\frac{l}{L} \sum_{i}\left(\frac{\tau_{i}+\tau_{i}^{s}+m_{i} M}{H^{\prime}-\max \left(0, e_{1}\right)}\right) \\
\tau_{i} & =\min \left(e_{i}+L^{\prime} / v, H^{\prime}\right)-e_{i} \\
\tau_{i}^{s} & =\min \left(e_{i}+2 L^{\prime} / v, H^{\prime}\right)-\left(e_{i}+L^{\prime} / v\right)
\end{aligned}
$$

where $\tau_{i}, \tau_{i}^{s}$ are the minimal train running times for train service $i$ and its symmetric train in the opposing direction and $M$ is the time supplement for each train stop needed for the passing of opposing trains. Here we cut off event times outside $H^{\prime}$. Further, $U$ is only considering the time span when trains are actually running (i.e. $\left.\max \left(0, e_{1}\right), H^{\prime}\right]$ starting with the first train departure $e_{1}$ - see Figure 4c).

The running time of each train can now be calculated as a function of the opposing trains and the capacity usage. Such equations can be more or less complicated. One advanced example can be found in Murali et al. (2010), but here we make use of a simple empirical equation which has been established in experimental studies by the Swedish Transport Administration (Banverket (2009)).

$$
r_{i}=\tau_{i}+m_{i} M+\frac{\max (0.2 U-0.06,0)}{60} \tau_{i} v
$$

This equation sums up (1) the minimal train running time with supplements for (2) the number of stops due to train meets and (3) line capacity usage. The third part will give a time supplement per travel distance, which is proportional to the capacity usage when $U>0.3$. As noted in Eliasson and Börjesson (2014), this relation is likely to underestimate the travel times at high capacity usages, but since maintenance windows will only be considered at low traffic densities we can disregard this deficiency. Equations (11) - (14) now give the values for determining the travel time differences $y^{d}$.

Using the above equations, we conclude this subsection with some illustrative examples. In Figure 4a the unmodified case (without maintenance window) is shown, with trains running every 90 minutes at a speed of $90 \mathrm{~km} / \mathrm{h}$. We study the time horizon $H^{\prime}=5$ and line stretch $L^{\prime}=100$ where there are originally 7 train meets (in the positive quadrant). Assuming a 5 minute time supplement for these stops $(M=5 / 60)$ and a meet / pass loop distance of $l=20 \mathrm{~km}$, the capacity usage is $U=0.32$, giving a negligible time supplement for capacity usage. In Figure $4 \mathrm{~b}$ the trains have been adjusted so as to give a central $2 \mathrm{~h}$ maintenance window. 


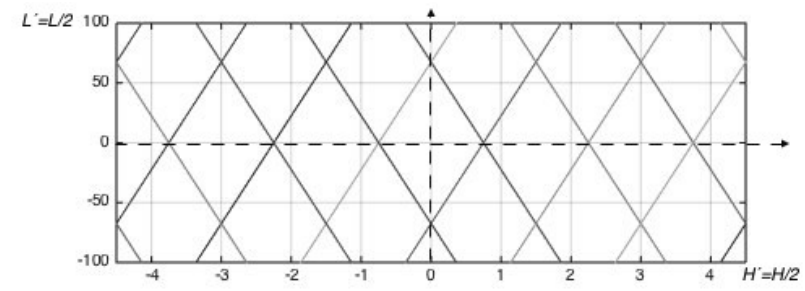

(a) Unmodified

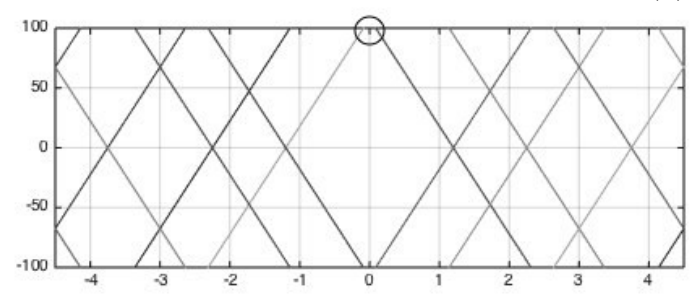

(b) $2 \mathrm{~h}$ window (one less train meet)

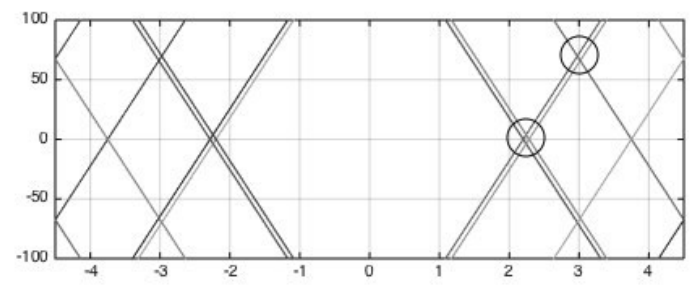

(d) $4 \mathrm{~h}$ window (double train crossings)

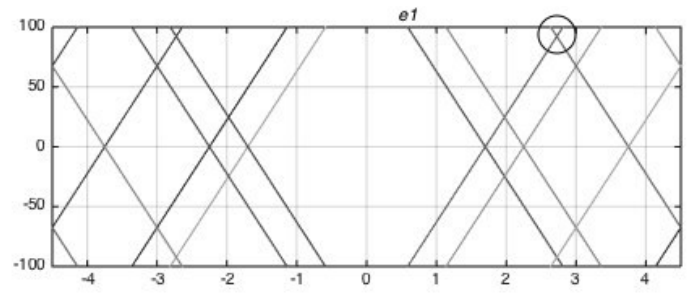

(c) 3h window (one more train meet)

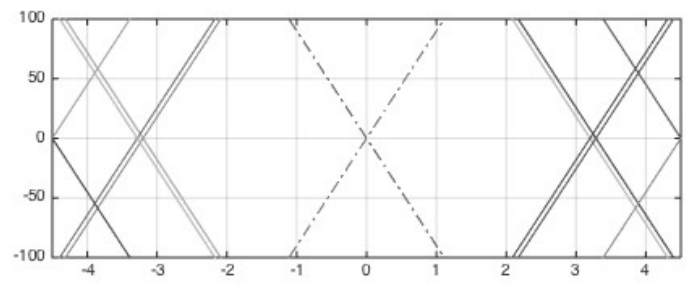

(e) $6 \mathrm{~h}$ window (rejected trains)

Figure 4: Freight traffic examples with increasing maintenance window size

Here the number of train meets is reduced by one (as marked in the figure), giving a small reduction in total travel time. The capacity usage is practically the same. In Figure $4 \mathrm{c}$ the central window size is further increased to $3 \mathrm{~h}$ (which allows for a $1 \mathrm{~h}$ peripheral maintenance window) and a new train meet is introduced (as marked). Here, two trains in each direction (one before and one after the window) have been adjusted with a total of $1.7 \mathrm{~h}$ and the capacity usage increases slightly as well as the total travel time. In the subsequent example (Figure 4d) a $4 \mathrm{~h}$ central maintenance window has been obtained, which forces two more trains to be adjusted (in order to uphold the necessary train separation). In this case it might be beneficial to operate the trains in a column fashion - letting the two nearby trains run in sequence in order to make better usage of opposing train stops at the marked train crossings. Finally, if a central window of $6 \mathrm{~h}$ is wanted, then the needed adjustment for the most affected trains is more than $2 \mathrm{~h}$. If the acceptable limit $q^{\max }$ is less, one train in each direction must be rejected and we get the situation as in Figure $4 \mathrm{e}$,

To illustrate further, we use the results from the previous examples and scale the rejection $\operatorname{cost} c^{r}$ as well as the time dependant operating cost $c^{d}$ towards the adjustment $\operatorname{cost} c^{a}$ as follows: $c^{r}=5 c^{a}, c^{d}=1.5 c^{a}$ (fictitious values). Then we can plot the marginal traffic cost $C^{t f}$ (red line) for the long distance freight traffic due to increasing maintenance window size as shown in Figure 5a. The slope changes are due to changes in number of train meets, when additional trains are affected and when train services are rejected.

In the same plot we have indicated how the maintenance cost $C^{m}$ (blue line) will be affected by the increased window size. Here we have used equation (9) over five $20 \mathrm{~km}$ track sections, each having a $3 \mathrm{~h}$ maintenance task with a $1 \mathrm{~h}$ overhead time (done outside of the possession) and an hourly cost rate $c_{j}=c^{a}$. The sum $C^{m}+C^{t f}$ (black line) shows that in this case the optimal window size is $3.5-4 \mathrm{~h}$. Depending on the maintenance volumes and the cost ratio between maintenance and train traffic $\left(c_{j} / c^{a}\right)$ different optimal maintenance window sizes will be obtained as outlined in Figure $5 \mathrm{~b}$. As expected, the optimal window size increases with increasing maintenance to traffic cost ratio. 


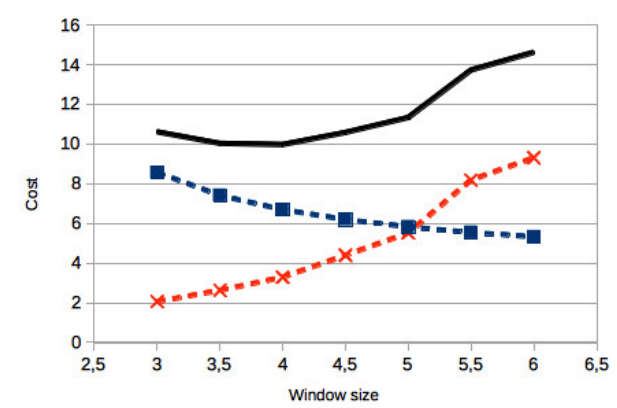

(a) Traffic and maintenance cost

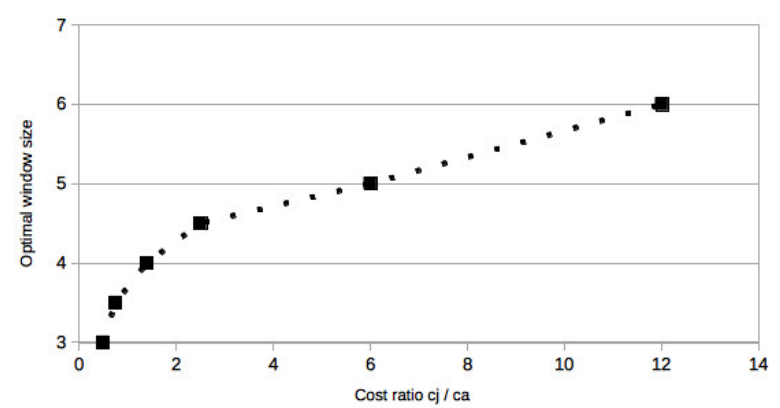

(b) Optimal window size

Figure 5: The effect of varying maintenance window size on traffic and maintenance cost (left) and how the maintenance to traffic cost ratio changes the optimal maintenance window size (right)

\subsection{Passenger traffic cost model}

In this subsection we describe a model for evaluating the effects of maintenance windows on regional passenger traffic. We make use of well-known methodology from transport economics ${ }^{2}$, adopting the same type of model as described in Eliasson and Börjesson (2014) and apply it on a micro scale - considering detailed travel demand, individual trains and alternate transport modes (cars and buses). The intended use is for studying the marginal response when making relatively small adjustments to a preferred (possibly existing) timetable. A typical situation is when considering to reject or reschedule an off peak train with few passengers, who then will face a decision of choosing another service or transport mode. The alternatives will have different perceived (generalized) cost depending on direct costs, comfort, travel and waiting time.

As starting point we have a demand function $\delta$ giving the distribution of travellers over time. We discretize into a set of time intervals $T$ (e.g. 15 minutes long) and let $\delta_{t}, t \in T$ be the share of travel demand in each time interval such that $\sum_{t \in T} \delta_{t}=1$. For each $t$ we also use a representative event time $e_{t}^{\delta} \in[0, H]$.

The generalized cost for a certain (train) service $i \in I$ is determined by the function $c_{i t}^{g}=p_{i}+\alpha_{i} r_{i}^{p}+\beta_{i} d_{i t}^{\delta}$ where $p_{i}$ is the (ticket) price, $r_{i}^{p}$ the passenger travel time and $d_{i t}^{\delta}=\left|e_{t}^{\delta}-e_{i}\right|$ the waiting time for passengers in time interval $t$. The parameters $\alpha_{i}$ and $\beta_{i}$ are values for travel and waiting time respectively.

When considering other transport modes, the generalized cost for those are calculated in the same way (using appropriate prices, times and values). If some transport mode will include change-overs, an additional cost will be applied for this. It is assumed that each traveller will then choose the transport service that minimizes the generalized cost and conforms with given travelling limitations. For example, some people might not have access to a car, while some car-owners might not accept a waiting time longer than a certain threshold.

From the obtained travel patterns we get a certain share of travellers $\delta_{i}$ for each (train) service $i$ and an average generalized cost $\bar{c}^{g}$ (weighted by the share of travellers) for all travellers. The total travel demand is a function of this cost and we assume the commonly used constant elasticity demand function $D(c)=\left(c / \bar{c}^{g 0}\right)^{\epsilon} D^{0}$ where $\bar{c}^{g 0}, D^{0}$ apply to the base case. The actual number of travellers per mode and (train) service is now given by $D_{i}=\delta_{i} D(c)$ and the consumer surplus (CS) can be calculated with the so called "rule of half" approximation $C S=\left[D\left(\bar{c}^{g 0}\right)+D\left(\bar{c}^{g 1}\right)\right] / 2 *\left(\bar{c}^{g 0}-\bar{c}^{g 1}\right)$.

The change in (train) service supply and the subsequent change in travel demand will also affect the transport operators. We define their net balance as fare revenues minus operating costs in the following way $P=\sum_{i}\left(D_{i} p_{i}-\gamma^{r} r_{i}-\gamma^{s} s_{i}\right)$, where $D_{i} p_{i}$ is the fare revenue, $\gamma^{r} r_{i}$ the time dependent cost and $\gamma^{s} s_{i}$ the distance dependent cost for service $i$. In our case, all trains will be operated the distance $s=L$. The producer surplus (PS) can now be calculated as $P S=P^{0}-P^{1}$.

\footnotetext{
${ }^{2}$ The research field of transport economics is attributed to John Robert Meyer and covered by several research journals, e.g. "Research in Transport Economics", and online resources. Many countries nowadays have elaborate appraisal methods for infrastructure and transportation investments based on such economical models.
} 
The total benefits are given by $C S+P S$, which we will use as the marginal cost $C^{t p}$ on passenger traffic when introducing maintenance windows

\section{Case study}

In this section we apply the previously described models on a real life instance 4 , namely the south-most part of the Northern Main Line in Sweden between the stations Gävle and Ljusdal (see Figure 6). On the stretch Ockelbo to Ljusdal - mainly single track - the Swedish Transport Administration is considering to introduce a $2 \mathrm{~h}$ maintenance window between 12 and 14 every normal week day, starting year 2017. The proposed maintenance window was based on a study of the current traffic - both freight and passenger - to find a favourable work time slot affecting as few trains as possible. In the following, we will first calculate the marginal effect on the maintenance cost, then on the freight traffic and finally on the regional passenger traffic. We do the calculation for a normal week day, occurring 48 weeks per year.

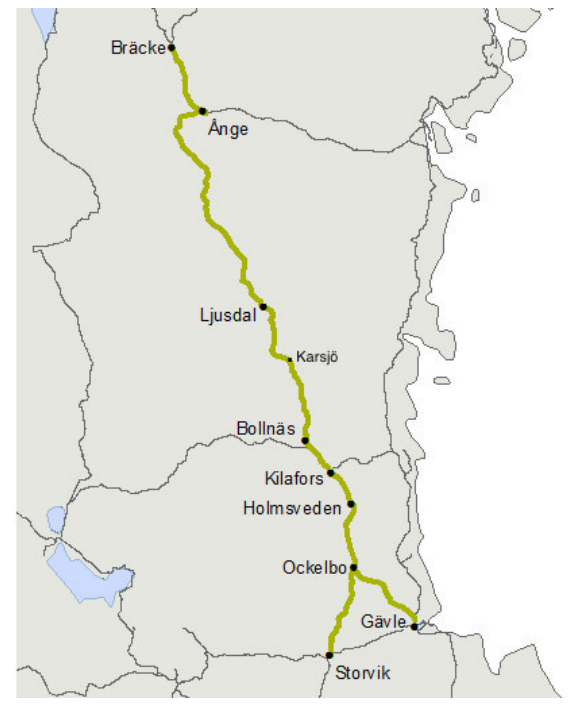

Figure 6: Southern part of Northern Main Line

\begin{tabular}{rrrr}
\hline$j$ & Task time & Volume & \# shifts \\
& $w_{j}[\mathrm{~h}]$ & $V_{j}[\mathrm{~h}]$ & $a_{j}^{n}$ \\
\hline 1 & 0.5 & 348 & 696 \\
2 & 1.0 & 1376 & 1376 \\
3 & 2.0 & 1687 & 843 \\
\hline
\end{tabular}

Table 2: Maintenance volume per task type $j$ for the stretch Ockelbo - Ljusdal

\begin{tabular}{ll}
\hline$k:$ Description & $\begin{array}{l}\text { Train free slots } \\
\text { Day; Evening; Night }\end{array}$ \\
\hline 1: Ljusdal-Karsjö $(28 \mathrm{~km})$ & $1 \mathrm{x} 1 \mathrm{~h} ; 1 \mathrm{x} 1 \mathrm{~h} ; 1 \mathrm{x} 2 \mathrm{~h}$ \\
2: Karsjö-Bollnäs $(35 \mathrm{~km})$ & $2 \mathrm{x} 1 \mathrm{~h} ;---; 2 \mathrm{x} 1 \mathrm{~h}$ \\
3: Bollnäs-Holmsveden $(33 \mathrm{~km})$ & $2 \mathrm{x} 1 \mathrm{~h} ;---; 1 \mathrm{x} 2 \mathrm{~h}$ \\
4: Holmsveden-Ockelbo $(22 \mathrm{~km})$ & $1 \mathrm{x} 5 \mathrm{~h} ; 1 \mathrm{x} 1.5 \mathrm{~h} ; 1 \mathrm{x} 7.5 \mathrm{~h}$ \\
\hline
\end{tabular}

Table 3: Train free slots per track section $k$ before introducing maintenance windows

Maintenance cost. The yearly volumes of maintenance work is given by Table 2 and the stretch has been divided into four sections, 22 - $35 \mathrm{~km}$ long, with varying possibilities for track access in the current timetable as shown in Table 3. We assume the work tasks are equally spread over the sections and over the $48 * 5=240$ normal week days.

First we calculate the daily cost increase for performing maintenance in small windows as given by the current timetable (see Table 3). We use an hourly cost rate $c_{j}=140 € / \mathrm{h}$, compensation factor $\rho^{w}=0.6$ for night time jobs and $30+30$ minute overhead time outside and inside the possession time $\left(u^{o}=u^{i}=0.5\right)$. Equation A.9 then gives $C^{m 0}=1385 €$ (cost change for current timetable vs nominal possession time).

With the proposed maintenance window, a saving (negative cost change value) is achieved for the short job types (half and hour long) on three of the four sections. We assume an additional transportation time between two jobs which increases the overhead time inside the possession with 15 minutes, giving $u^{i}=0.75$. With these assumptions, again using A.9 we get $C^{m 1}=-152 €$ (cost change for maintenance window vs nominal possesion time). Thus the total daily benefit when introducing the proposed maintenance windows as compared to the current situation is $C^{m 0}-C^{m 1}=1537 €$. This benefit is mainly due to not having to split $2 \mathrm{~h}$ jobs and being able to perform all maintenance on day time.

\footnotetext{
${ }^{3}$ Other factors as marginal effects on environment, accidents etc when travels by car, bus and train is changing can also be included.

${ }^{4}$ This section is based on the report Lidén (2015b) written for the Swedish Transport Administration, which studies several different options. Here we only present the main results. A currency rate of 10 SEK : $1 €$ has been used.
} 
Freight traffic cost. Three north-bound freight trains will need to be either rerouted or rescheduled. The net result is estimated to prolong the rolling stock circulations with $2.25 \mathrm{~h}$ at a cost of $200 € / \mathrm{h}$, giving a cost increase for freight traffic $C^{t f}=450 €$ every operating day. No trains need to be rejected and the travel time differences are negligible. Hence we have a simplified version of equation $(10)$ and need not consider runtime supplements due to capacity limitations etc.

Passenger traffic cost. The regional passenger trains currently have departures from end stations every even hour in each direction. Hence, the departures at noon must be rejected when introducing the $2 \mathrm{~h}$ maintenance window between 12 and 14. Since the traffic as well as passenger counts are almost symmetric we analyse one direction (southbound trains) and multiply the result by two. To account for passenger flows to surrounding trains we study the $H=6 \mathrm{~h}$ time period 9:00 - 15:00, which will include the $|I|=3$ train services at 10:00, 12:00 and 14:00. According to given travel statistics the noon trains have about 95 passengers, while the surrounding trains have slightly more passengers $(\approx 100$ at 10:00 and $\approx 110$ at 14:00). From this we construct a discretized travel demand curve as shown in Figure 7. Note that this is just one demand curve that would give the reported passenger count 5 and that the trains at 10:00, 12:00 and 14:00 will be used by passengers who want to travel [09:00, 11:00], [11:00, 13:00] and [13:00, 15:00] respectively.

The train running times are $r_{i}=100 / 60 \mathrm{~h}$ between the end stations (having a distance of $165 \mathrm{~km}$ and an average train speed $v=100 \mathrm{~km} / \mathrm{h}$ ). The average passenger will travel a distance of $90 \mathrm{~km}^{6}$ which takes $r_{i}^{p}=90 / 100 \mathrm{~h}$ and costs $p_{i}=9 €$ with the train. With car the travel takes $1.1 \mathrm{~h}$ and with bus $1.35 \mathrm{~h}$. The cost parameters for travellers and operators are given in Table 4 which give the generalized costs for different travellers as shown in Figure 8. For those who want to travel exactly when a train departs (e.g. 10:00) there is no waiting time and the generalized cost is simply $c^{g}=p_{i}+\alpha_{i} r_{i}^{p}=9+6.1 * 0.9=14.5 €$ (see subsection 6.2). For those with the longest waiting time (1h) the cost increases with $\beta_{i} * 1=1.3 €$ to become $15.8 €$.

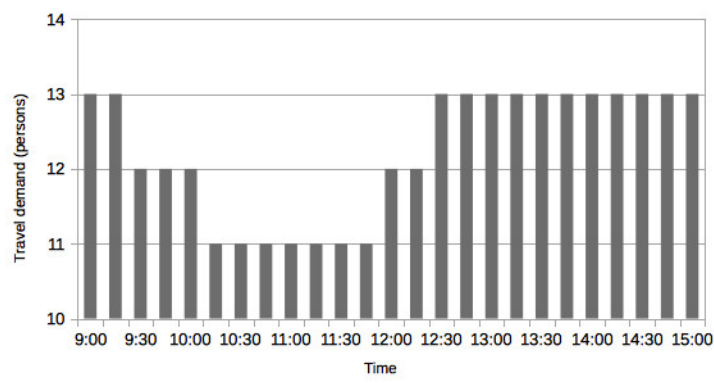

Figure 7: Constructed travel demand $\left(\delta_{i} D^{0}\right)$ per 15 minute interval between 9:00 and 15:00, giving the reported passenger counts

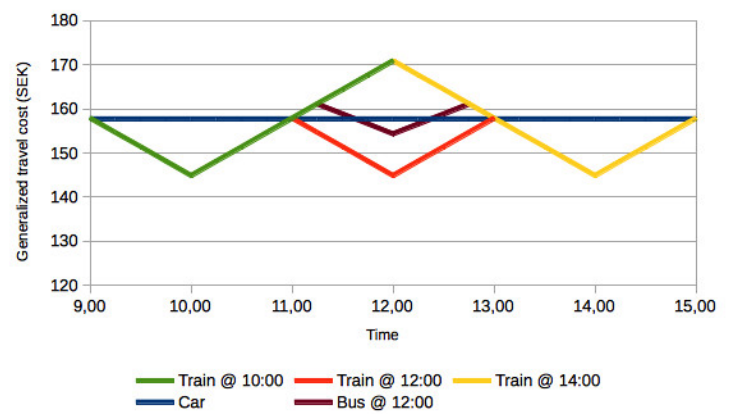

Figure 8: Generalized travel cost for different travellers and transport modes. Currency rate is $10 \mathrm{SEK}: 1 €$

\begin{tabular}{lc}
\hline Parameter & $\begin{array}{c}\text { Value } \\
\text { (train; bus; car })\end{array}$ \\
\hline In-vehicle time, $\alpha$ & $6.1 ; 4.3 ; 7.3 € / \mathrm{h}$ \\
Waiting time, $\beta$ & $1.3 ; 0.9 ;-€ / \mathrm{h}$ \\
Change-over time & $-; 14.4 ;-€ / \mathrm{h}$ \\
Demand elasticity, $\epsilon$ & -0.7 \\
\hline
\end{tabular}

a: Travellers

\begin{tabular}{lc}
\hline Parameter & $\begin{array}{c}\text { Value per vehicle } \\
\text { (train; bus) }\end{array}$ \\
\hline Operating time, $\gamma^{r}$ & $263 ; 73 € / \mathrm{h}$ \\
Distance cost, $\gamma^{s}$ & $1.26 ; 0.54 € / \mathrm{km}$ \\
Standstill cost & $184 ; 0 € / \mathrm{h}$ \\
\hline
\end{tabular}

b: Operators

Table 4: Cost parameters (source: ASEK $\sqrt{2015}$ )

\footnotetext{
${ }^{5}$ The sensitivity of the results could have been studied by varying the demand curve, but other factors like cost settings, availability of bus replacements etc was judged to have larger impact.

${ }^{6}$ based on travel statistics supplied by the regional traffic operator
} 
The generalized cost for car travel does not vary over time since there is no waiting time, while bus trave ${ }^{7}$ will exhibit the same structure as train travels. If using true values for car travel (including depreciation) the car cost will be so high that no one would choose the car. Instead, we set the generalized cost for car travel to the highest train travel value, since this will give the largest number of mode changes from public transport to car. This is also in line with the reasoning that most car users do not value their true cost but only consider their direct costs (petrol etc). We also make a further assumption that half of the travellers have access to a car (based on car owner statistics for the considered regional area).

Given the above assumptions we can now calculate the consumer and producer surplus using the equations in subsection 6.2 and get $C^{t p}=C S+P S=-58.6+-194.1=-252.7 €$ (in one traffic direction). The average generalized cost for all travellers $\left(\bar{c}^{g}\right)$ increases from 15.17 to $15.36 €$ which gives a reduction in total travel demand (D) from 306 (all by train) to 303 persons distributed between train/bus/car as 235/45/23. The net effect for the consumers is rather small, mostly since replacement traffic by bus is offered. The operators get lower fare revenues (due to the car travellers) and also a higher cost for running the buses as well as having trains standing still during the maintenance window duration.

Summing up. We can now add up the different parts to see that the suggested maintenance windows will reduce the daily maintenance costs by about $1500 €$ while the traffic costs will increase by $450 €$ for the freight traffic and $2 * 250=500 €$ for passenger traffic. From this we conclude that the total benefit is positive for introducing the suggested maintenance windows. Note however, that several other factors may also need to be analysed and studied in order to obtain a complete picture. Such factors, possibly case specific, can be consequences for environment, attractiveness, safety and reliability.

\section{Summary and discussion}

In this paper we have described a quantitative method for comparing conflicting capacity needs from maintenance and transportation in railway networks. This will enable a balanced dimensioning of train free slots for maintenance work possessions as well as assessment of different timetable solutions. We have also shown how the models can be used when analysing planning problems that appear in real life instances. The specific purpose has been to study the effects of introducing maintenance windows, but we believe the models are applicable whenever work possessions and train traffic are interfering and need to be evaluated in a common framework in any type of railway network. Of special interest is to use the models as part of an objective function in different types of optimization problems. We have only discussed a homogeneous case with one line and one maintenance window on a single track line. The same methodology can be used on double track lines, where the effects on traffic is much less if single track operation is acceptable while maintenance is performed. Although we have studied a Swedish case, there should be no trouble applying the methods to any timetabled railway operation. As a continuation we intend to use the presented cost calculation methods for heterogeneous situations on longer lines and networks in order to optimally schedule and construct patterns of maintenance windows considering a future transportation demand as well as maintenance needs.

\section{Acknowledgements}

This work has been performed as part of the research project "Efficient planning of railway infrastructure maintenance", funded by the Swedish Transport Administration (Trafikverket) and conducted within the national research program "Capacity in the Railway Traffic System". Invaluable contributions from all experts and reference persons at Trafikverket, especially Lars Brunsson, as well as numerous research colleagues are thankfully noted.

\footnotetext{
${ }^{7} 20 \%$ of the bus travellers are assumed to get a 10 minute change-over.
} 


\section{References}

Albrecht, A. R., Panton, D. M., Lee, D. H., Mar. 2013. Rescheduling rail networks with maintenance disruptions using problem space search. Computers \& Operations Research 40 (3), 703-712.

URL http://dx.doi.org/10.1016/j.cor.2010.09.001

ASEK, 2015. Appraisal guidelines. Swedish Transport Administration.

URL http://www.trafikverket.se/ASEK

Banverket, Sep. 2009. Beräkningshandledning - Hjälpmedel för samhällsekonomiska bedömningar inom järnvägssektorn (BVH 706, F09-10922/SA10).

Ben-Daya, M., Kumar, U., Murthy, D., 2016. Introduction to Maintenance Engineering: Modelling, Optimization and Management. Wiley.

URL https://books.google.se/books?id=JxqpCwAAQBAJ

Boland, N., Kalinowski, T., Waterer, H., Zheng, L., Dec. 2013. Mixed integer programming based maintenance scheduling for the Hunter Valley coal chain. Journal of Scheduling 16 (6), 649-659. URL http://dx.doi.org/10.1007/s10951-012-0284-y

Borraz-Sánchez, C., Klabjan, D., 2012. Strategic Gang Scheduling for Railroad Maintenance. CCITT, Center for the Commercialization of Innovative Transportation Technology, Northwestern University. URL http://ntl.bts.gov/lib/46000/46100/46128/CCITT_Final_Report_Y201.pdf

Budai, G., Huisman, D., Dekker, R., 2006. Scheduling preventive railway maintenance activities. Journal of the Operational Research Society 57 (9), 1035-1044.

URL http://dx.doi.org/10.1057/palgrave.jors.2602085

Chen, S., Ho, T., Mao, B., May 2013. Maintenance schedule optimisation for a railway power supply system. International Journal of Production Research 51 (16), 4896-4910. URL http://dx.doi.org/10.1080/00207543.2013.774501

Chen, S.-k., Ho, T.-k., Mao, B.-h., Bai, Y., Jul. 2014. A bi-objective maintenance scheduling for power feeding substations in electrified railways. Transportation Research Part C: Emerging Technologies 44, 350-362. URL http://dx.doi.org/10.1016/j.trc.2014.04.016

Dekker, R., Mar. 1996. Applications of maintenance optimization models: a review and analysis. Reliability Engineering \& System Safety 51 (3), 229-240.

URL http://dx.doi.org/10.1016/0951-8320(95)00076-3

Durango-Cohen, P. L., Madanat, S. M., Oct. 2008. Optimization of inspection and maintenance decisions for infrastructure facilities under performance model uncertainty: A quasi-Bayes approach. Transportation Research Part A: Policy and Practice 42 (8), 1074-1085.

URL http://dx.doi.org/10.1016/j.tra.2008.03.004

EIM-EFRTC-CER Working Group, ., Oct. 2012. Market Strategies for Track Maintenance \& Renewal. Tech. Rep. 2353 7473-11, CER - Community of European Railway and Infrastructure Companies.

URL http://www.cer.be/publications/studies/studies-details/report-from-the-eim-efrtc-cer-working-group-onmarket-strategies-for-track-maintenance-renewal/

Eliasson, J., Börjesson, M., Nov. 2014. On timetable assumptions in railway investment appraisal. Transport Policy 36, 118-126. URL http://dx.doi.org/10.1016/j.tranpol.2014.08.008

Forsgren, M., Aronsson, M., Gestrelius, S., Aug. 2013. Maintaining tracks and traffic flow at the same time. Journal of Rail Transport Planning \& Management 3 (3), 111-123.

URL http://dx.doi.org/10.1016/j.jrtpm.2013.11.001

Gustavsson, E., Patriksson, M., Strömberg, A.-B., Wojciechowski, A., Önnheim, M., Jan. 2014. Preventive maintenance scheduling of multi-component systems with interval costs. Computers \& Industrial Engineering. URL http://dx.doi.org/10.1016/j.cie.2014.02.009

Higgins, A., Oct. 1998. Scheduling of railway track maintenance activities and crews. The Journal of the Operational Research Society $49(10), 1026$ URL http://dx.doi.org/10.2307/3010526

Lidén, T., Oct. 2015a. Railway infrastructure maintenance - a survey of planning problems and conducted research. Transportation Research Procedia 10C, 574 - 583, 18th Euro Working Group on Transportation, EWGT 2015, 14-16 July 2015, Delft, The Netherlands.

URL http://dx.doi.org/10.1016/j.trpro.2015.09.011

Lidén, T., apr 2015b. Samhällsekonomisk värdering av servicefönster på Norra Stambanan, sträckan Ockelbo-Ljusdal. Tech. Rep. PM, Dnr ITN-2013-00177, Linköping University, Dept of Science and Technology.

Liu, X., Lovett, A., Dick, T., Rapik Saat, M., Barkan, C., Jun. 2014. Optimization of ultrasonic rail-defect inspection for improving railway transportation safety and efficiency. Journal of Transportation Engineering 1014 (10). URL http://dx.doi.org/10.1061/(ASCE) TE.1943-5436.0000697

Lyngby, N., Hokstad, P., Vatn, J., Jan. 2008. RAMS management of railway tracks. In: Misra, P. K. B. (Ed.), Handbook of Performability Engineering. Springer London, pp. 1123-1145. URL http://link.springer.com/chapter/10.1007/978-1-84800-131-2_68

Murali, P., Dessouky, M., Ordóñez, F., Palmer, K., 2010. A delay estimation technique for single and double-track railroads. Transportation Research Part E: Logistics and Transportation Review 46 (4), 483-495.

URL http://dx.doi.org/10.1016/j.tre.2009.04.016

Peng, F., Ouyang, Y., Dec. 2012. Track maintenance production team scheduling in railroad networks. Transportation Research 
Part B: Methodological 46 (10), 1474-1488.

URL http: //dx.doi.org/10.1016/j.trb.2012.07.004

RailNetEurope, Nov. 2013. Guidelines for coordination / publication of works and possessions.

URL http://www.rne.eu/tl_files/RNE_Upload/Downloads/RFC\%20Guidelines/Guidelines\%20for\%20Coordination-

Publication\%20of\%20Works\%20and\%20Possessions.pdf

Savelsbergh, M., Waterer, H., Dall, M., Moffiet, C., Nov. 2014. Possession assessment and capacity evaluation of the Central Queensland Coal Network. EURO Journal on Transportation and Logistics, 1-35.

URL http: //dx.doi.org/10.1007/s13676-014-0066-0

van Zante-de Fokkert, J. I., den Hertog, D., van den Berg, F. J., Verhoeven, J. H. M., Apr. 2007. The Netherlands schedules track maintenance to improve track workers' safety. Interfaces 37 (2), 133-142.

URL http://dx.doi.org/10.1287/inte.1060.0246

Zhao, J., Chan, A., Stirling, A., Madelin, K., Jan. 2006. Optimizing policies of railway ballast tamping and renewal. Transportation Research Record: Journal of the Transportation Research Board 1943 (-1), 50-56.

URL http: //dx.doi.org/10.3141/1943-07

\section{AppendixA. Detailed maintenance cost model}

Here we present a general maintenance cost model for multiple track sections and with full flexibility regarding the overhead times. The basic notation is the same as given in Section 5 , but extended with additional sub- and superscripts. The equations are given and numbered in the same order, i.e. (1) corresponds to (A.1).

The complete notation is as follows (note again that superscript $n$ denote the nominal (standard possession) case and $w$ the considered window case):

$J \quad$ Set of maintenance task (job) types $j$

$K \quad$ Set of track sections $k$ with uniform maintenance and traffic demand

$V_{j k} \quad$ Maintenance volume (time) for job type $j$ on track section $k$

$w_{j} \quad$ Task time for job $j$

$t_{j}^{n} \quad$ Nominal possession time (corresponding to the task time) for task $j$

$u_{j}^{n i}, u_{j}^{n o} \quad$ Overhead time, inside $(i)$ and outside $(o)$ a nominal possession, for job $j$

$a_{j k}^{n} \quad$ Number of work shifts for job type $j$ on track $k$ with nominal possession time $t_{j}^{n}$

$t_{j k}^{w} \quad$ Window time for job type $j$ on track section $k$

$u_{j k}^{w i}, u_{j k}^{w o} \quad$ Overhead time, inside $(i)$ and outside $(o)$ the considered window time $t_{j k}^{w}$, for job $j$ on track section $k$

$a_{j k}^{w} \quad$ Number of work shifts for job type $j$ on track section $k$ with the considered window time $t_{j k}^{w}$

$T_{j k}^{n}, T_{j k}^{w} \quad$ Total work time with $t_{j}^{n}$ and $t_{j k}^{w}$ respectively

$c_{j} \quad$ Hourly cost rate (daytime) for job type $j$

$\rho_{j k}^{w} \quad$ Compensation factor if the window is placed on evening, night or weekend working hours

$C^{m} \quad$ Total cost difference when using the considered window times vs nominal possession times

The basic relations are:

$$
\begin{aligned}
V_{j k} & =w_{j} a_{j k}^{n} \\
T_{j k}^{n} & =\left(u_{j}^{n o}+t_{j}^{n}\right) a_{j k}^{n}=\left(u_{j}^{n o}+u_{j}^{n i}+w_{j}\right) a_{j k}^{n} \\
T_{j k}^{w} & =\left(u_{j k}^{w o}+t_{j k}^{w}\right) a_{j k}^{w}
\end{aligned}
$$

where A.1 give the maintenance volume for each task type and track section, while A.2 and A.3 give the total work time for the nominal and the window case respectively. Equality of the work volume gives the relation for the number of work shifts:

$$
\begin{aligned}
V_{j k} & =w_{j} a_{j k}^{n}=\left(t_{j k}^{w}-u_{j k}^{w i}\right) a_{j k}^{w} \\
\Rightarrow a_{j k}^{w} & =a_{j k}^{n} * \frac{w_{j}}{t_{j k}^{w}-u_{j k}^{w i}}
\end{aligned}
$$

By taking A.3 minus A.2 and using equation A.5 we two alternate formulas for calculating the difference in total work hours: 


$$
\begin{aligned}
& T_{j k}^{w}-T_{j k}^{n}=a_{j k}^{n}\left[w_{j} * \frac{t_{j k}^{w}+u_{j k}^{w o}}{t_{j k}^{w}-u_{j k}^{w i}}-\left(t_{j}^{n}+u_{j}^{n o}\right)\right] \\
& T_{j k}^{w}-T_{j k}^{n}=a_{j k}^{n} * \frac{u_{j k}^{w o}+u_{j k}^{w i}}{t_{j k}^{w}-u_{j k}^{w i}}\left[w_{j}+\left(u_{j k}^{w i}-t_{j k}^{w}\right) \frac{u_{j}^{n o}+u_{j}^{n i}}{u_{j k}^{w o}+u_{j k}^{w i}}\right]
\end{aligned}
$$

Finally, we get the general expression for calculating the cost difference vs the nominal case:

$$
\begin{aligned}
C^{m} & =\sum_{j k} c_{j}\left[\left(1+\rho_{j k}^{w}\right) T_{j k}^{w}-T_{j k}^{n}\right]=\sum_{j k} c_{j}\left[T_{j k}^{w}-T_{j k}^{n}+\rho_{j k}^{w} T_{j k}^{w}\right] \\
& =\sum_{j k} c_{j} a_{j k}^{n}\left[w_{j} A-u_{j}^{n}+\rho_{j k}^{w} w_{j} B\right]=\sum_{j k} c_{j} V_{j k}\left[A-u_{j}^{n} / w_{j}+\rho_{j k}^{w} B\right]
\end{aligned}
$$

where

$$
\begin{aligned}
& A=\frac{u_{j k}^{w o}+u_{j k}^{w i}}{t_{j k}^{w}-u_{j k}^{w i}}, \quad u_{j}^{n}=u_{j}^{n o}+u_{j}^{n i}, \quad B=\frac{t_{j k}^{w}+u_{j k}^{w o}}{t_{j k}^{w}-u_{j k}^{w i}} \quad \text { in the general case } \\
& A=\frac{u_{j k}^{w}}{t_{j k}^{w}} \\
& B=\frac{t_{j k}^{w}+u_{j k}^{w}}{t_{j k}^{w}} \quad \text { for the "all-outside" case } \\
& A=\frac{u_{j k}^{w}}{t_{j k}^{w}-u_{j k}^{w}}, \\
& B=\frac{t_{j k}^{w}}{t_{j k}^{w}-u_{j k}^{w}} \quad \text { for the "all-inside" case }
\end{aligned}
$$

By "all-outside" we mean that all overhead time is done outside of the possession (i.e. $u^{n i}=u^{w i}=0$ ), while for the "all-inside" all the overhead work is done inside the possession time (i.e. $u^{n o}=u^{w o}=0$ ). Note that these cases only differ in the form of the $A$ and $B$ factors. In addition we can see that the condition for achieving a saving (i.e. a negative cost change) is $A+\rho_{j k}^{w} B<u_{j}^{n} / w_{j}$, allowing us to calculate a break-even window size $t^{w}$. 